\title{
Associating gene expressions with curcuminoid biosynthesis in turmeric
}

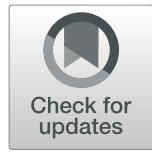

\author{
Dipendra Kumar Ayer ${ }^{{ }^{*}}$ (D), Kaushal Modha', Vipulkumar Parekh², Ritesh Patel', Gopal Vadodariya', \\ Vinita Ramtekey ${ }^{1}$ and Arpit Bhuriya'
}

\begin{abstract}
Background: Biologically important curcuminoids viz curcumin, demethoxycurcumin, and bisdemethoxycurcumin in turmeric rhizome have several health benefits. Pharmaceutical industries synthesize curcuminoids manipulating gene expressions in vitro or in vivo because of their medicinal importance. In this experiment, we studied the gene expressions involved in the curcuminoid biosynthesis pathway in association with curcuminoid yield in turmeric rhizome to study the impact of individual gene expression on curcuminoid biosynthesis.

Results: Gene expressions at the different growth stages of turmeric rhizome were association tested with respective curcuminoid contents. Gene expression patterns of diketide-CoA synthase (DCS) and multiple curcumin synthases (CURSs) viz curcumin synthase 1 (CURS1), curcumin synthase 2 (CURS2), and curcumin synthase 3 (CURS3) were differentially associated with different curcuminoid contents. Genotype and growth stages showed a significant effect on the gene expressions resulting in a significant impact on curcuminoid balance in turmeric rhizome. DCS and CURS3 expression patterns were similar but distinct from CURS1 and CURS2 expression patterns in turmeric rhizome. DCS expression had a significant positive and CURS3 expression had a significant negative association with curcumin, demethoxycurcumin, bisdemethoxycurcumin, and total curcuminoid in turmeric rhizome. CURS1 expression had a negative association with curcumin whereas CURS2 expression showed a positive association with demethoxycurcumin.

Conclusions: The effects of DCS and CURS expressions are not always positive with different curcuminoid contents in turmeric rhizome. DCS expression has a positive and CURS3 expression has a negative association with curcuminoids. CURS1 and CURS2 are also associated with curcumin and demethoxycurcumin synthesis. This mechanism of co-expression of diketide-CoA synthase and multiple curcumin synthases in turmeric rhizome has a significant effect on curcuminoid balance in different turmeric cultivars. Further experiment will explore more insights; however, association-based test results from this experiment can be useful in improving curcuminoid yield in turmeric rhizome or in vitro through the application of genetic engineering and biotechnology.
\end{abstract}

Keywords: Association, Curcuminoids, Diketide-CoA synthase, Gene regulation, Multiple curcumin synthases

\footnotetext{
* Correspondence: dip_ayer@hotmail.com

'Department of Genetics and Plant Breeding, N. M. College of Agriculture,

Navsari Agricultural University, Navsari, Gujarat 396450, India

Full list of author information is available at the end of the article
}

\section{Springer Open}

(c) The Author(s). 2020 Open Access This article is licensed under a Creative Commons Attribution 4.0 International License, which permits use, sharing, adaptation, distribution and reproduction in any medium or format, as long as you give appropriate credit to the original author(s) and the source, provide a link to the Creative Commons licence, and indicate if changes were made. The images or other third party material in this article are included in the article's Creative Commons licence, unless indicated otherwise in a credit line to the material. If material is not included in the article's Creative Commons licence and your intended use is not permitted by statutory regulation or exceeds the permitted use, you will need to obtain permission directly from the copyright holder. To view a copy of this licence, visit http://creativecommons.org/licenses/by/4.0/. 


\section{Background}

Turmeric (Curcuma longa L. syn. Curcuma domestica Val.) is a rhizomatous, herbaceous, and perennial plant belonging to the Zingiberaceae family which includes almost 110 species [1]. Turmeric is also known by different names in different countries such as Haldi in India and Besar in Nepal. Turmeric is widely cultivated in the tropical and subtropical regions of the world including India, China, Bangladesh, Nepal, Sri Lanka, Pakistan, Asian subcontinents, and the Caribbean and Latin American regions [2]. The use of turmeric rhizome is mentioned in the Vedic culture in Indian subcontinents and still has extensive use as a culinary spice, coloring agent, food preservative, natural dye in the food industry, cosmetics, medicine, and religious rituals $[3,4]$. The first evidence of biological effects of turmeric have been attributed to its constituent curcumin, discovered and isolated almost two centuries ago [5]; however, recent studies suggest that most of the pharmaceutical properties of turmeric depend on its biologically active constituents, curcuminoids viz curcumin, demethoxycurcumin, and bisdemethoxycurcumin [6]. The turmeric rhizome contains 3-5\% curcuminoids and up to $5 \%$ essential oils and resins [7] where commercially available turmeric powder is generally composed of about $77 \%$ curcumin, $17 \%$ demethoxycurcumin, and 3\% bisdemethoxycurcumin [6]. Curcumin, a major curcuminoid from turmeric rhizome, is proven for its significance as antiinflammatory, antioxidant, antimutagenic, antidiabetic, antibacterial, antiviral, antifungal, hepatoprotective, kidney disease treatment, expectorant, anti-cancerous, treating conditions like arthritis, inflammation to Alzheimer's disease, and influencing gene transcription and expression, cell signaling pathway, and epigenetic mechanisms $[3,8-$ 12]. Turmeric is a minor crop in terms of its contribution towards food security; however, the curcuminoids from this spice crop are attractive targets for metabolic engineering and pharmaceutical applications [13].

Curcuminoids are biologically synthesized through a phenylpropanoid pathway in turmeric [14]; however, several studies were also carried out successfully for producing curcuminoids in vitro through an artificial curcuminoid biosynthesis pathway $[13,15,16]$. There are several other upstream section enzyme genes involved in the curcuminoid biosynthesis pathway which catalyze the synthesis of early substrates (feruloyl-CoA/ $p$-coumaroyl-CoA) [14, 17, 18]; however, downstream section enzyme genes involved in the curcuminoid biosynthesis pathway play a major role in catalyzing the formation of curcuminoid scaffold in turmeric rhizome. Diketide-CoA synthase $(D C S)$, a type III PKS, and multiple curcumin synthases (CURSs) viz curcumin synthase1 (CURS1), curcumin synthase 2 (CURS2), and curcumin synthase 3 (CURS3) involved in the downstream section of the curcuminoid biosynthesis pathway in turmeric were identified and characterized where DCS synthesizes feruloyldiketide-CoA/ $p$-coumaroyldiketide CoA and CURS1, CURS2, and CURS3 then converts diketide-CoA esters into different curcuminoid scaffolds viz curcumin, demethoxycurcumin, and bisdemethoxycurcumin [19, 20]. The authors also reported that relative expression of DCS, CURS1, and CURS2 were higher in rhizome than leaf whereas CURS3 expression was almost similar in rhizome and leaf. The gene expression studies suggested that the content of curcuminoids in turmeric cultivars depends on the expression balance of these four major enzyme genes (DCS, CURS1, CURS2, and CURS3) in turmeric rhizome in addition to the availability of the substrates for curcuminoid scaffold biosynthesis. Transcriptomics studies in turmeric have shed light on the identification and validation of multiple curcumin synthases involved in the curcuminoid biosynthetic pathway in turmeric [17, 18, 21]. More novel type III PKS genes have been identified recently, such as CLPKS9 and CLPKS10 [22], CLPKS1and CLPKS2 [18], and CLPKS11 [23] which may have a potential role in curcuminoid scaffold biosynthesis; however, the difference in the contents of curcuminoids among the species can be explained by the changes in the expression of genes encoding diketide-CoA synthase and multiple curcumin synthases at the branching point of the curcuminoid biosynthesis pathway in turmeric [24]. The variation in curcuminoid content among the various lines and cultivars of $C$. longa was reported to be caused by hybridization and introgression [25], agro-climatic variation [26], genotype and environment interaction [27], and microenvironment (below soil surface near root zone) and macroenvironment (above soil surface) interaction [28]; however, the effects of tissue-specific gene expressions on curcuminoid biosynthesis are still unknown. Gene expressions of diketide-CoA synthases and multiple curcumin synthases in turmeric were also found to be influenced by tissue-specific (leaves and rhizome) and temporal (growth stages) variations within a cultivar [29]; this may have an influence on curcuminoid balance. CURS expression was found regardless of the variation in the curcumin content in different turmeric cultivars at different agroclimatic regions, and expressions were positively correlated with curcumin content in turmeric cultivars within an environment at different stages of growth [30]; however, the effect of individual $D C S$ and CURS gene expression on curcuminoid yield is still unexplored. The first-stage study of this experiment revealed that differential DCS and CURS expressions can be predictively associated with curcuminoid content in different turmeric cultivars to study the relationship between target gene expressions and curcuminoid yield in turmeric rhizome [31]. Specific genes associated with target quantitative traits are commonly known as trait- 
associated genes (TAGs) which can be defined by the robust linear regression analysis through an association test between continuous traits and mRNA expression [32]. Huber's M-estimator-based robust regression method [33] is useful for identifying TAGs. In this experiment, we studied DCS and CURS gene expressions in association with variable curcuminoid content in turmeric rhizome at different stages of growth to find out the impact of individual gene expression on curcuminoid yield in terms of magnitude and direction using a statistical model. Gene expressions or transcript abundance was regarded as genotypic values whereas associated changes in curcuminoids were regarded as phenotypic values at different growth stages while performing the association-based test. The association-based test results from this experiment can also be useful for improving curcuminoid yield in turmeric rhizome or in vitro through the application of genetic engineering and biotechnology.

\section{Methods}

\section{General experimental conditions}

Rhizome samples of turmeric cultivars (GNT-2, Pratibha, and NDH-98) were selected randomly for gene expression study and curcuminoid analysis at three different growth stages in field conditions. The first stage was determined to be the active vegetative growth stage (SI, 4 months after planting), the second stage was at the active rhizome development stage (SII, 5 months after planting), and the third stage was at the maturity or senescence stage (SIII, 6 months after planting). Three biological samples (rhizomes) from each cultivar at three stages of growth under study were taken out of the soil for RNA isolation, isolated RNA was reverse transcribed into complementary deoxyribonucleic acid (cDNA), and gene expression was studied through RT-qPCR in the Department of Genetics and Plant Breeding and Biotechnology Laboratory at NAU, Gujarat, India, during 2017-2018. The cultivars used in this experiment were denoted as biological sets NDH-98 (N), GNT-2 (G), and Pratibha (P). From each biological sample, two technical replicates were utilized for further downstream analysis through $\mathrm{qPCR}$. The gene expression results obtained from the RT-qPCR assay were further used for association tests with curcuminoid yield in turmeric rhizome. Plant sampling procedures for RNA isolation were carried out following the recommended guidelines [34]. Technical sampling procedures and RT-qPCR procedures were followed as per the MIQE guidelines for the gene expression study $[35,36]$.

\section{Rhizome sampling and curcuminoid content analysis}

At each stage of study viz SI, SII, and SIII, rhizome fingers were excised from the mother rhizome with a sterile knife and washed, packed into aluminum foil along with identification number, and immediately dipped into liquid nitrogen $\left(-196^{\circ} \mathrm{C}\right)$ container for RNA isolation, cDNA synthesis, and gene expression study in the laboratory. The remaining portions of individually sampled rhizomes were cleaned, sliced into pieces, sun-dried for 5-7 days, and made into a fine powder using the grinder for curcuminoid content analysis (curcumin, demethoxycurcumin, and bisdemethoxycurcumin) through HPLC using individual curcuminoid standards (Sigma Aldrich) at the Food Quality Testing Laboratory (FQTL), NAU, Navsari, Gujarat. For curcuminoid analysis, $1.0 \mathrm{~g}$ turmeric powder of each cultivar was dissolved in $50 \mathrm{ml}$ of $100 \%$ methanol separately and then mixed and vortexed for $30 \mathrm{~min}$. The solution is then filtered and injected in the Thermo HPLC Surveyor instrument (Thermo Scientific) for individual curcuminoid measurement at $425-\mathrm{nm}$ wavelength. Laboratory analysis was performed at room temperature $\left(25-30^{\circ} \mathrm{C}\right)$.

\section{RNA isolation and CDNA synthesis}

Total RNA was isolated at three different growth stages (SI, SII, and SIII) of three turmeric cultivars under study using the RNeasy ${ }^{\circ}$ Plant Mini Kit (Qiagen, Germany) involving on-column genomic DNA digestion step of DNase I (Qiagen) treatment following the manufacturer's protocol. The integrity and size distribution of the total RNA purified were checked by $1.2 \%$ denaturing formaldehyde agarose (FA) gel electrophoresis and staining with ethidium bromide visualizing two sharp bands of $28 \mathrm{~S}$ rRNA to $18 \mathrm{~S}$ RNA in a 2:1 ratio. RNA purity check and quantification were done using the Nanodrop 2000 instrument (Thermo Scientific) which showed the acceptable purity for each biological sample $\left(\mathrm{A}_{260} / \mathrm{A}_{280}\right.$ of 1.9 to 2.1). From the total RNA, the mRNA with the poly-A tail was reverse transcribed into cDNA using oligo dT primers during the reverse transcription step. cDNA was synthesized in $20 \mu \mathrm{l}$ reaction using $2 \mu \mathrm{l}$ of total isolated RNA (1 ng in final solution) with $4 \mu \mathrm{l}$ of $5 \mathrm{X}$ cDNA synthesis buffer (1X final), $2 \mu \mathrm{l}$ of $2 \mathrm{X}$ dNTP mix (500 $\mu \mathrm{M}$ each), $1 \mu \mathrm{l}$ of anchored oligo dT primer (for mRNA reverse transcription), $1 \mu \mathrm{l}$ RT enhancer, $1 \mu \mathrm{l}$ verso enzyme mix, and water up to $20 \mu \mathrm{l}$. cDNA synthesis protocol involved a single 30-min cycle of polymerase enzyme activity at $42^{\circ} \mathrm{C}$ followed by one additional cycle of $2 \mathrm{~min}$ at $95^{\circ} \mathrm{C}$ for inactivation of enzyme (Verso cDNA Synthesis Kit, Thermo Scientific).

\section{Quantification of transcript abundance through RT-qPCR assays}

RT-qPCR assays at three different stages were carried out along with gene-specific and reference gene primers (Additional file 1: Table S2) which were validated in turmeric RNA samples. All the qPCR assays of four target 
genes as well as reference genes at each stage were included in a single 96-well plate (Thermo Scientific) for minimizing error while quantifying the abundance of cDNA in technical replicates of each biological sample. A standard qPCR protocol and plate setup were performed on CFX96 real-time PCR thermocycler using the CFX Manager software (Bio-Rad). For finding out transcript abundance in different turmeric samples, qPCR assay comprised $10 \mu \mathrm{l}$ of $2 \mathrm{X}$ PowerUp ${ }^{\mathrm{Tm}} \mathrm{SYBR}^{\mathrm{m}}$ Green $^{-}$ Master Mix (Applied Biosystems), $0.5 \mu \mathrm{M}$ of each genespecific forward and reverse primers along with reference gene Actin, $2 \mu \mathrm{l}$ of 10 -fold diluted cDNA as a template, and remaining quantity of nuclease-free water (HiMedia) to make a final volume of $20 \mu \mathrm{l}$. qPCR conditions for gene expression study were as follows: heatlabile uracil-DNA glycosylase (UDG) activation at $50{ }^{\circ} \mathrm{C}$ for $2 \mathrm{~min}$ followed by Dual-Lock ${ }^{\mathrm{Tm}}$ DNA polymerase activation at $95^{\circ} \mathrm{C}$ for $2 \mathrm{~min}$, and 40 cycles of denaturation at $95^{\circ} \mathrm{C}$ for $15 \mathrm{~s}$ followed by combined anneal/extend temperature of $60^{\circ} \mathrm{C}$ for $1 \mathrm{~min}$. For studying the specificity of the products, the final melting curve analysis of 65 to $95^{\circ} \mathrm{C}$ with a $0.5^{\circ} \mathrm{C}$ increment was used according to the manufacturer's protocol (Bio-Rad, CFX96 instrument), and the products were also confirmed on $1.2 \%$ agarose gel electrophoresis. Quantification cycle $\left(C_{\mathrm{q}}\right)$ and normalized gene expression values obtained in the CFX Manager software were used for further analysis. Negative controls (no template control (NTC)) were also included to detect any false positives during reverse transcription (RT) and qPCR assays. The data generated along with the $C_{\mathrm{q}}$ values were subjected to the CFX Manager (v.3.1, Bio-Rad) software package which includes mathematical models for estimating the relative quantification and normalization of qPCR data for gene expression analysis $[37,38]$. Gene study feature in the CFX Manager software was set to a regulation threshold of 2-fold change and a $p$ value threshold of 0.05 for finding out any significant variations in the gene expressions. DCS and CURSs melt peak curves were studied for the specificity of the products, and gel electrophoresis was also performed for the validation of the qPCR products using the reference gene Actin.

\section{Association-based test between gene expressions and curcuminoids}

In this experiment, diketide-CoA synthase $(D C S)$ and multiple curcumin synthases (CURS1, CURS2, and CURS3) or CURSs gene expression patterns were studied at three different growth stages viz SI (active vegetative stage), SII (active rhizome development stage), and SIII (maturity or senescence stage) among three turmeric cultivars significantly differing in curcuminoid (curcumin, demethoxycurcumin, and bisdemethoxycurcumin) contents in the rhizome. The robust regression analysis was used by taking normalized gene expression values from the RT-qPCR analysis as explanatory or independent variables and curcuminoid contents (curcumin, demethoxycurcumin, bisdemethoxycurcumin, and total curcuminoid) obtained from HPLC analysis as a response or dependent variables for identifying genes that are more closely associated with curcuminoid biosynthesis in turmeric, also known as trait-associated genes (TAGs). A separate association-based test was also done for the total curcuminoid content in turmeric rhizome which was estimated by summing up the individual curcuminoid content in each turmeric rhizome at each growth stage. The association between curcuminoids and mRNA expressions was analyzed using Huber's Mestimator-based ROBUSTREG procedure [39] in SAS University Edition $\left(\mathrm{SAS}^{\circ}\right.$ Studio 3.71, $\mathrm{SAS}^{\oplus}$ Institute Inc.). The general linear regression model for the association-based test [32] using gene expression data was as follows:

Trait $_{i}=\beta_{0}+\beta_{1} \quad$ Expression $_{1 i}+\ldots+\beta_{p} \quad$ Covariate $_{p i}+\varepsilon_{i}$, $\varepsilon_{i} \sim\left(N, \sigma^{2}\right)$

where $i$ represents the individuals; Expression $_{i}$ indicates the normalized gene expression value; Trait ${ }_{i}$ represents each continuous trait such as curcumin, demethoxycurcumin, bisdemethoxycurcumin, and total curcuminoid;

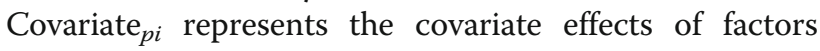
other than error factors $\left(\varepsilon_{i}\right)$; beta $(\beta)$ in a linear regression model is a standardized coefficient indicating the magnitude of the correlation between an independent and dependent variable; $N$ and $\sigma^{2}$ represent the analysis of variance assumption of normal distribution and common standard deviation, respectively. Additional tests like the rho $(\rho)$ test based on the robust $F$-test and $R_{n} \wedge 2$ test based on the Wald-type tests were also carried out to measure the association of covariates on response variables. The SAS codes and dataset used during the data analysis are given in Additional file 1: Annex 1.

\section{Results}

\section{Curcuminoid analysis in turmeric cultivars}

Based on the high-performance liquid chromatography (HPLC) analysis, turmeric cultivars "GNT-2" and "Pratibha" were not significantly different for curcumin and total curcuminoid content whereas "NDH-98" was with relatively lower curcumin and lower total curcuminoid content than "GNT-2" and "Pratibha" (Table 1). There was no significant difference among the cultivars for demethoxycurcumin content; however, the highest bisdemethoxycurcumin was in "GNT-2" followed by "Pratibha" and below detection level in "NDH-98" turmeric rhizome. Irrespective of the curcuminoid contents, the rhizome yield of short-growth-duration cultivar "NDH-98" was the highest (33-34 $\mathrm{t} \mathrm{ha}^{-1}$ ) followed by long-growth-duration cultivars "GNT-2" (28-29t ha $\left.{ }^{-1}\right)$ and "Pratibha" (23-24t 
Table 1 Curcuminoid contents in turmeric cultivars at different stages under study

\begin{tabular}{|c|c|c|c|c|c|c|}
\hline Sample ID & $\begin{array}{l}\text { Curcumin } \\
(\%)\end{array}$ & $\begin{array}{l}\text { Demethoxy curcumin } \\
\text { (\%) }\end{array}$ & $\begin{array}{l}\text { Bisdemethoxycurcumin } \\
\text { (\%) }\end{array}$ & $\begin{array}{l}\text { Total curcuminoid } \\
\text { (\%) }\end{array}$ & $\begin{array}{l}\text { Rhizome yield } \\
\left(\mathrm{t} \mathrm{ha}^{-1}\right)\end{array}$ & $\begin{array}{l}\text { Growth duration } \\
\text { (days) }\end{array}$ \\
\hline NDH-98_SI & 0.27 & 0.76 & $\mathrm{BDL}$ & 1.03 & & \\
\hline NDH-98_SII & 0.1 & 0.36 & $\mathrm{BDL}$ & 0.46 & & \\
\hline NDH-98_SIII & 0.04 & 0.08 & $\mathrm{BDL}$ & 0.12 & & \\
\hline $\begin{array}{l}\text { Average } \mathrm{NDH}- \\
98\end{array}$ & $0.14 b(25 \%)$ & 0.40a (75\%) & $\mathrm{BDL}$ & $0.54 b(100 \%)$ & $33-34$ & 240 \\
\hline GNT-2_SI & 2.31 & 0.71 & 1.14 & 4.16 & & \\
\hline GNT-2_SII & 0.76 & 0.07 & 0.15 & 0.98 & & \\
\hline GNT-2_SIII & 0.81 & 0.18 & 0.24 & 1.23 & & \\
\hline Average GNT-2 & $1.29 a(61 \%)$ & 0.32a (15\%) & $0.51 \mathrm{a}(24 \%)$ & $2.12 \mathrm{a}(100 \%)$ & $28-29$ & 256 \\
\hline Pratibha_SI & 0.56 & 0.11 & 0.14 & 0.81 & & \\
\hline Pratibha_SII & 1.29 & 0.17 & 0.14 & 1.6 & & \\
\hline Pratibha_SIII & 1.33 & 0.22 & 0.24 & 1.79 & & \\
\hline $\begin{array}{l}\text { Average } \\
\text { Pratibha }\end{array}$ & $1.06 a(76 \%)$ & $0.17 a(12 \%)$ & $0.17 b(12 \%)$ & $1.40 \mathrm{ab}(100 \%)$ & $23-24$ & 256 \\
\hline
\end{tabular}

" $\mathrm{a}$ " and " $\mathrm{b}$ " are the significance letters which indicate that values with the same letters in a column are statistically not significant from each other at $p<0.05$. [NDH-98 has lower curcumin (25\%), higher demethoxycurcumin (75\%), and negligible bisdemethoxycurcumin; GNT-2 has higher curcumin (61\%) and lower bisdemethoxycurcumin (24\%) and demethoxycurcumin (15\%); Pratibha has higher curcumin (76\%) and lower demethoxycurcumin (12\%) and bisdemethoxycurcumin (12\%); GNT-2 and Pratibha have similar and higher total curcuminoid yield than NDH-98] NDH-98, GNT-2, and Pratibha turmeric cultivars

$B D L$ Below the detection limit during HPLC analysis, SI 4 months after planting, SII 5 months after planting, SIII 6 months after planting

$\mathrm{ha}^{-1}$ ) (Table 1). The results showed that the higher turmeric rhizome yield does not necessarily mean higher curcuminoids in the turmeric cultivars. The chromatograms showing individual curcuminoid detection in the HPLC system are given in Additional file 2.

\section{Gene expressions in turmeric rhizome at different growth stages}

There were no off products in the qPCR analysis based on the melt peak curves which was further confirmed by gel electrophoresis showing a single band of PCR product, and the data was considered reliable for further analysis. The results of the qPCR analysis are given in Additional file 2. Comparing the gene expression profiles in different turmeric cultivars, DCS (2.94-fold) and CURS3 (2.87-fold) expressions were upregulated at SII as compared with SI and SIII; however, CURS1 (1.88-fold) and CURS2 (1.05 fold) were expressed at a lower level in GNT-2. In NDH98, DCS (0.88-fold) and CURS3 (1.39-fold) expressions were lower; however, CURS1 (2.30-fold) and CURS2 (3.83-fold) expressions were higher at SII as compared with SI and SIII. In Pratibha, DCS (1.56-fold), CURS2 (0.76-fold), and CURS3 (0.79-fold) were expressed at a lower level; however, CURS1 (2.22 fold) expression was upregulated at SII as compared with SI and SIII (Fig. 1 and Additional file 1: Table S1). Generally, the gene expressions were increasing from active vegetative stage to rhizome development stage (SI to SII) and decreasing at maturity or senescence stage (SIII) under study except that DCS expression was decreasing throughout the growth stages in NDH-98, CURS2 expression was increasing throughout the growth stages in GNT-2, and CURS3 expression was decreasing throughout the growth stages in Pratibha (Fig. 1). These patterns in each cultivar might have some significant role to play for curcuminoid yield in different turmeric cultivars.

\section{Pooled gene expressions in turmeric cultivars}

The highest DCS expression was in higher curcumin yielding cultivar GNT-2 (1.55-fold) followed by Pratibha (1.04-fold) and the least in low curcumin yielding cultivar NDH-98 (0.66-fold) over the growth stages under study. CURS1 and CURS2 gene expressions were highest in NDH-98 (1.34-fold and 2.65-fold, respectively) followed by GNT-2 (0.92-fold and 0.74-fold, respectively) and Pratibha (0.84-fold and 0.49-fold, respectively). CURS3 expressions were lower than DCS expressions in all the cultivars over growth stages with the highest expression in GNT-2 (1.29-fold) followed by NDH-98 (0.91-fold) and Pratibha (0.77-fold). Among all the genes under study, CURS2 expressions were lower in Pratibha (0.48-fold) and GNT-2 (0.74-fold), however significantly higher in NDH-98 (2.65-fold). The results of pooled gene expressions over growth stages are in Fig. 2 and Additional file 1: Table S1. The results showed that GNT-2 and Pratibha, higher curcuminoid yielding cultivars, had a higher $D C S$ expression with relatively lower CURS1, CURS2, and CURS3 expressions opposite to that 


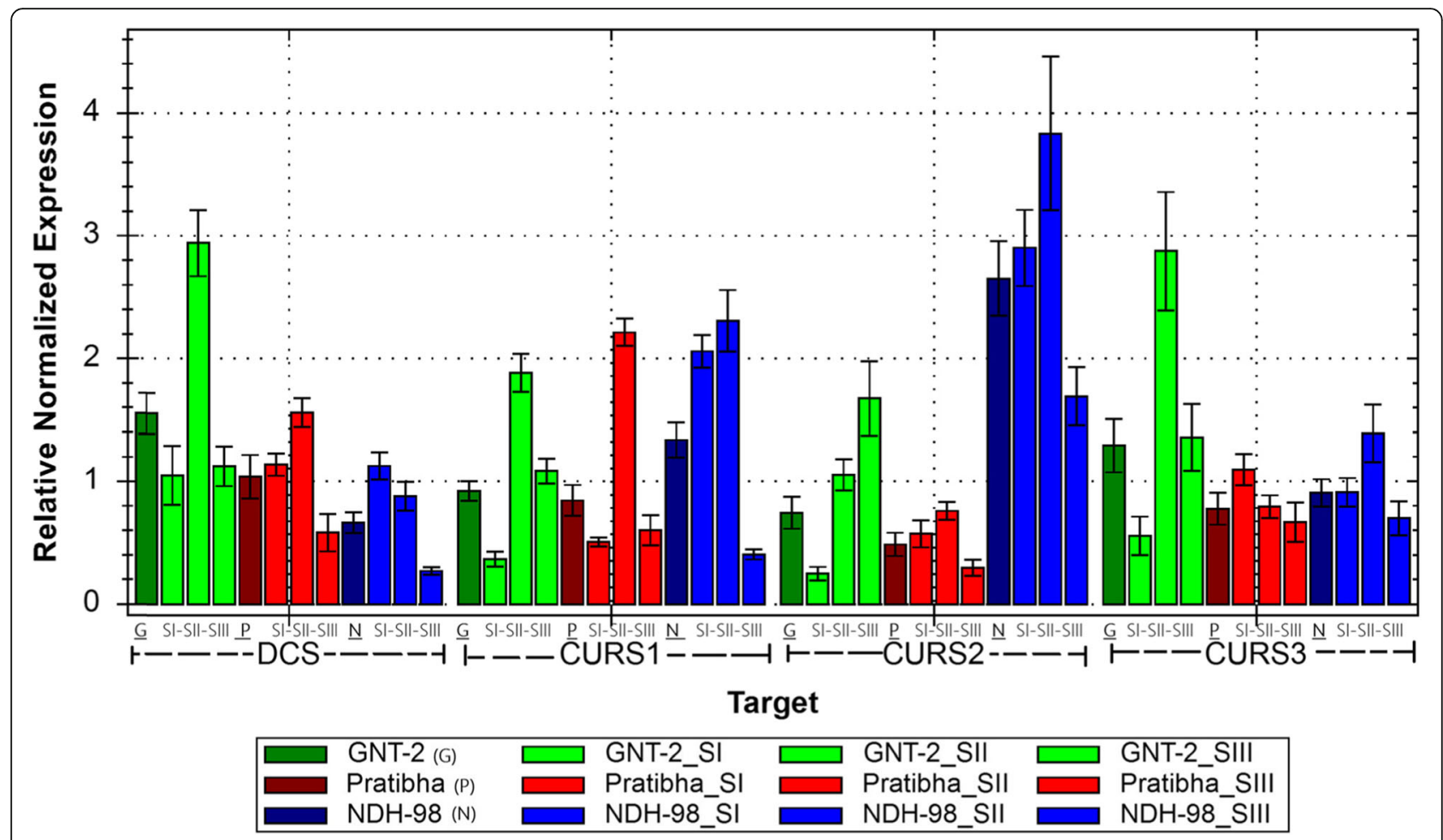

Fig. 1 Comparative gene expression analysis in turmeric cultivars at three stages of growth. Gene expressions were normalized to the reference gene Actin. Green colored bars represent GNT-2, red-colored bars represent Pratibha, and dark blue colored bars represent NDH-98. The first bar in each gene family is the average of the three stages SI, SII, and SIII of each cultivar, i.e., GNT-2 (G), Pratibha (P), and NDH-98 (N). In NDH-98, DCS expression is decreasing at all stages of growth from SI to SIII, CURS1, and CURS2 expression is higher at SI and SII and decreased at SIII whereas higher expression of CURS3 at SII stages under study. In the case of GNT-2, DCS, CURS1, and CURS3 are highly expressed at SII than SI and SIII, the CURS2 expression level is increasing throughout the growth stages from SI to SIII where DCS and CURS3 have almost equal expression level at SII in GNT-2. For Pratibha, DCS, CURS1, and CURS2 gene expressions are higher at SII as compared with SI and SIII, and CURS3 gene expression is decreasing at all stages of growth from SI to SIII. A significant amount of gene expression variation was observed during SII (5 months after planting) among the cultivars

of NDH-98, relatively lower curcuminoid yielding cultivar, which depicted lower DCS expression with relatively higher CURS1, CURS2, and CURS3 expressions (Fig. 2). There was no significant change in DCS, CURS1, CURS2, and CURS3 gene expressions between GNT-2 and Pratibha (higher curcumin and total curcuminoid yielding cultivars) at all stages of growth: however, their expressions differed in NDH-98 (lower curcumin and total curcuminoid yielding cultivar) (Table 2). DCS expression was found downregulated $(-2.35$ - and -1.57 fold) whereas CURS2 expression was found upregulated (3.57- and 5.46-fold) in lower curcumin and lower total curcuminoid yielding cultivar (NDH-98) as compared with higher curcumin and higher total curcuminoid yielding cultivars (GNT-2 and Pratibha) and vice versa (Table 2). There was no significant change in the CURS3 expression $(<2$-fold change) among the cultivars.

\section{Cluster analysis of DCS and CURSs gene expressions}

Cluster analysis of the gene expressions of three turmeric cultivars at three different growth stages revealed that DCS and CURS3 expression patterns were similar but distinct from CURS1 and CURS2 expression patterns in turmeric rhizome (Fig. 3). Similar results were obtained when gene expression was studied in two turmeric cultivars, GNT-2 and NDH-98, after 6 months of planting in field conditions [31].

\section{$D C S$ and CURSs gene expressions associated with curcuminoid biosynthesis in turmeric}

There was a significant effect of DCS, CURS1, and CURS3 gene expressions on curcumin content at $p<$ 0.01 . DCS had a positive linear association whereas CURS1 and CURS3 expressions had a negative linear association with curcumin. The covariate effect of CURS1 and CURS2 expressions on curcumin was also found significant at $p<0.01$ although the correlation was significant at $p<0.08$. Thus, DCS had a significantly positive whereas CURS1 and CURS3 expressions had a significantly negative association with curcumin yield in turmeric rhizome. Co-regulated expressions of CURS1 and 


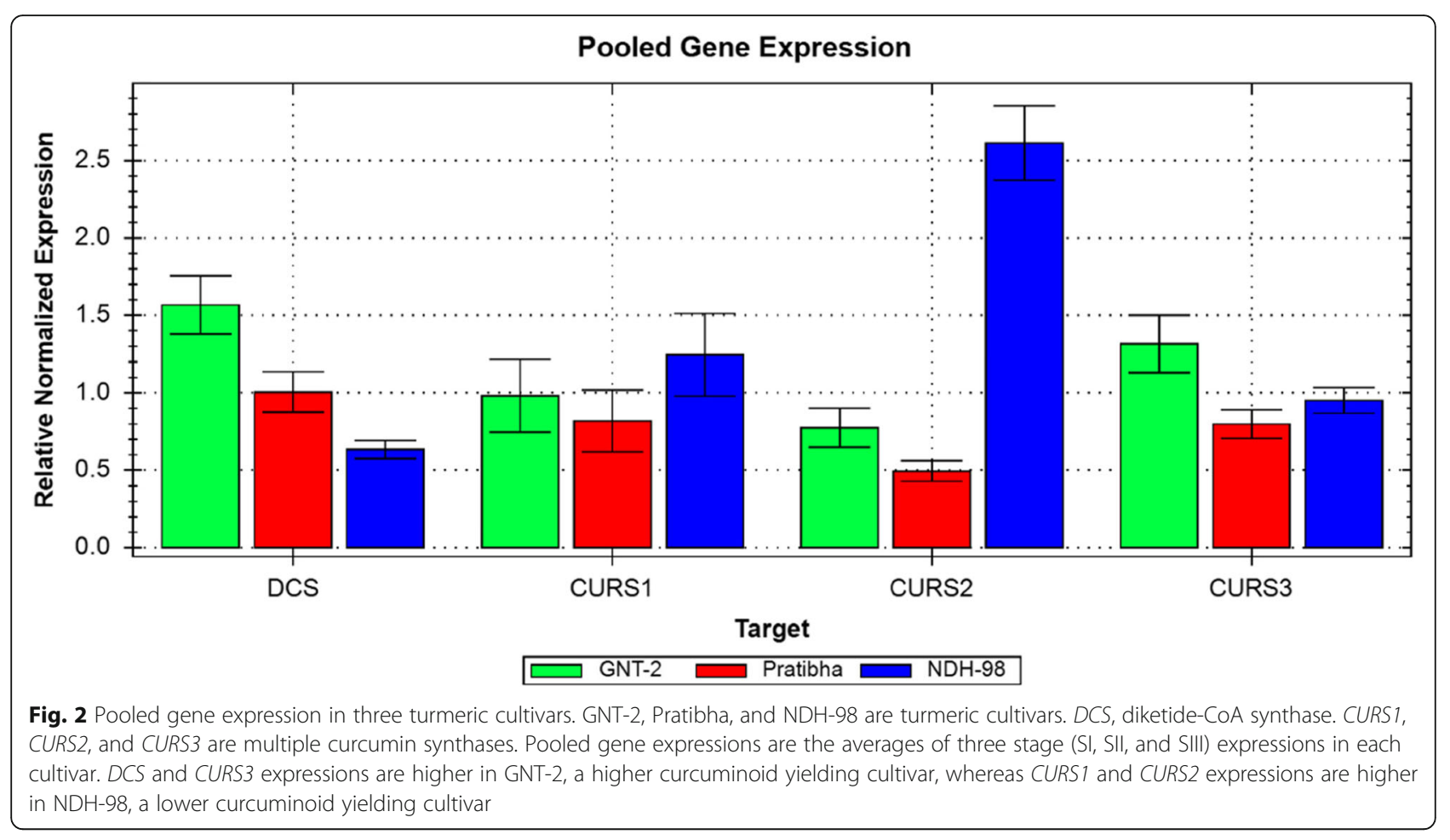

CURS2 were also found significantly associated with curcumin synthesis in turmeric rhizome (Table 3).

For demethoxycurcumin, DCS and CURS2 expressions had a significant positive association whereas CURS3 expressions had a significant negative association with demethoxycurcumin at $p<0.01$. The covariate effect of
CURS1 and CURS2 expressions on demethoxycurcumin was also found highly significant $(p<0.01)$. Thus, DCS and CURS2 expressions had significant positive associations whereas CURS3 expression had a significant negative association with demethoxycurcumin. Co-regulated expression of CURS1 and CURS2 also had a significant

Table 2 DCS and CURSS gene regulation in turmeric rhizome over growth stages

\begin{tabular}{|c|c|c|c|c|c|c|}
\hline Target & Experimental sample & Regulation & $p$ value & Exceeds $p$ value threshold & Compared to regulation threshold & Control sample \\
\hline Actin & GNT-2 & NA & 0.790985 & Yes & No change & Pratibha \\
\hline CURS1 & GNT-2 & 1.09 & 0.179227 & Yes & No change & Pratibha \\
\hline CURS2 & GNT-2 & 1.53 & 0.192329 & Yes & No change & Pratibha \\
\hline CURS3 & GNT-2 & 1.66 & 0.003796 & No & No change & Pratibha \\
\hline DCS & GNT-2 & 1.50 & 0.369600 & Yes & No change & Pratibha \\
\hline Actin & NDH-98 & NA & 0.496892 & Yes & No change & Pratibha \\
\hline CURS1 & $\mathrm{NDH}-98$ & 1.59 & 0.730277 & Yes & No change & Pratibha \\
\hline CURS2 & NDH-98 & 5.46 & 0.000001 & No & Upregulated & Pratibha \\
\hline CURS3 & NDH-98 & 1.17 & 0.395052 & Yes & No change & Pratibha \\
\hline DCS & NDH-98 & -1.57 & 0.044860 & No & No change & Pratibha \\
\hline Actin & NDH-98 & NA & 0.689920 & Yes & No change & GNT-2 \\
\hline CURS1 & NDH-98 & 1.45 & 0.036328 & No & No change & GNT-2 \\
\hline CURS2 & NDH-98 & 3.57 & 0.000027 & No & Upregulated & GNT-2 \\
\hline CURS3 & NDH-98 & -1.43 & 0.022002 & No & No change & GNT-2 \\
\hline DCS & NDH-98 & -2.35 & 0.000368 & No & Downregulated & GNT-2 \\
\hline
\end{tabular}

" + " or no sign in the regulation column represents upregulation (higher expression) of a gene in the current sample as compared with the control sample "-" sign indicates downregulation (lower expression) of a gene in the current sample as compared with the control sample

Upregulation of a "gene" in experimental sample as compared with control also indicates the downregulation of that same "gene" in the control sample as compared with experimental sample and vice versa. Gene expressions at different stages of growth viz SI, SII, and SIII for each cultivar were pooled together for comparative gene regulation study 


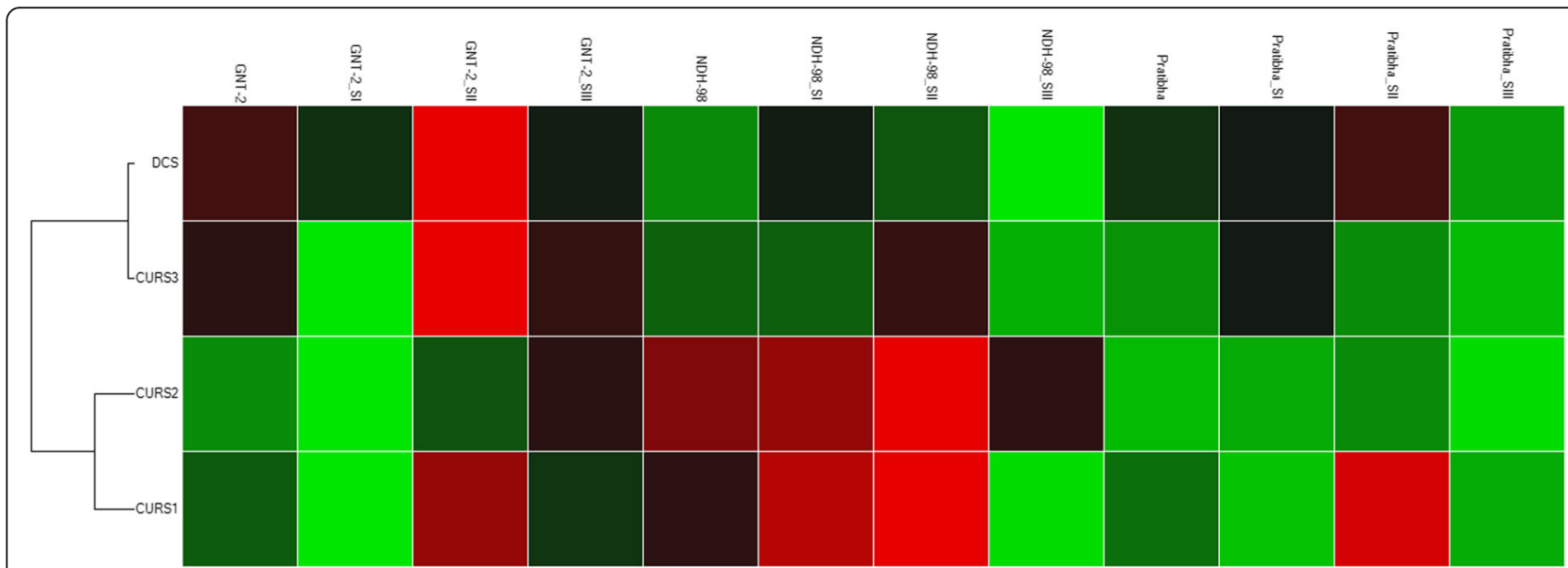

Fig. 3 Cluster gram showing the association between the gene expressions in turmeric at three growth stages. NDH-98, GNT-2, and Pratibha are three turmeric cultivars. SI, 4 months after planting; SII, 5 months after planting; SIII, 6 months after planting. Upregulation (higher expression) is shown by a red square, downregulation (lower expression) by a green square, and no regulation by a black square. The lighter the shade of color, the greater the relative expression difference. Gene expression patterns of DCS and CURS3 were more closely associated and distant from CURS1 and CURS2 gene expression patterns among the genotypes at all stages of growth. The upregulation of most of the genes was found at SII as compared with other states under study. GNT-2, NDH-98, and Pratibha expressions are the average expressions of all three stages

impact on the demethoxycurcumin content in the turmeric rhizome (Table 4).

DCS $(p<0.09)$ depicted a positive effect whereas CURS3 $(p<0.01)$ showed a significant negative effect on bisdemethoxycurcumin content. The covariate effects of CURS1 and CURS2 expression on bisdemethoxycurcumin were also found non-significant at $p<0.05$. Thus, DCS expression had a positive effect and CURS3 expression had a significant negative effect on bisdemethoxycurcumin content in turmeric rhizome (Table 5).

Only DCS and CURS3 expressions had a significant effect $(p<0.01)$ on the total curcuminoid content in turmeric rhizome where DCS had a significant positive linear association and CURS3 had a significant negative linear association with total curcuminoid. The covariate effect of CURS1 and CURS2 expression was found non-

Table 3 Association-based test of DCS and multiple curcumin synthases with curcumin

\begin{tabular}{|c|c|c|c|c|c|c|c|}
\hline \multirow[t]{2}{*}{ Parameter } & \multirow{2}{*}{$\begin{array}{l}\text { Class } \\
\text { label }\end{array}$} & \multicolumn{3}{|c|}{ Main effects } & \multicolumn{3}{|c|}{ CURS1 and CURS2 as a covariate } \\
\hline & & Estimate & Chi-square & $\mathrm{Pr}>\mathrm{ChiSq}$ & Estimate & Chi-square & $\mathrm{Pr}>\mathrm{ChiSq}$ \\
\hline Intercept & & 1.1091 & 486.32 & $<.0001$ & 1.4185 & 327.39 & $<.0001$ \\
\hline Growth stage & $\mathrm{SI}$ & 0.1039 & 4.05 & 0.0442 & -0.1792 & 4.53 & 0.0333 \\
\hline Growth stage & SII & 0.4701 & 57.26 & $<.0001$ & 0.0073 & 0.01 & 0.936 \\
\hline Growth stage & SIII & 0 & & & 0 & & \\
\hline Genotype & GNT-2 & 1.0375 & 342.2 & $<.0001$ & 1.1168 & 161.13 & $<.0001$ \\
\hline Genotype & $\mathrm{NDH}-98$ & -0.2774 & 14.84 & 0.0001 & -0.616 & 61.29 & $<.0001$ \\
\hline Genotype & Pratibha & 0 & & & 0 & & \\
\hline$D C S$ & & 0.9126 & 82.3 & $<.0001$ & 0.6182 & 26.03 & $<.0001$ \\
\hline CURS1 & & -0.3392 & 12.48 & 0.0004 & 0 & & \\
\hline CURS2 & & -0.0033 & 0.01 & 0.9371 & 0 & & \\
\hline CURS3 & & -1.3922 & 335.16 & $<.0001$ & -1.2216 & 153.92 & $<.0001$ \\
\hline \multicolumn{8}{|c|}{ Reduced parameter robust linear test for curcumin } \\
\hline Rho & & & & & 4.1143 & 5.16 & 0.0759 \\
\hline$R_{n} \wedge 2$ & & & & & 27.0998 & 27.1 & $<.0001$ \\
\hline
\end{tabular}

$\operatorname{Pr}<$ ChiSq approximately predicts the associated probability level after the selected variable has been entered or removed $\operatorname{Pr}$ Probability, ChiSq Chi-square, Rho association or correlation, $R_{n} \wedge 2$ robust Wald-type association test 
Table 4 Association-based test of DCS and multiple curcumin synthases with demethoxycurcumin

\begin{tabular}{|c|c|c|c|c|c|c|c|}
\hline \multirow[t]{2}{*}{ Parameter } & \multirow{2}{*}{$\begin{array}{l}\text { Class } \\
\text { label }\end{array}$} & \multicolumn{3}{|c|}{ Main effects } & \multicolumn{3}{|c|}{ CURS1 and CURS2 as a covariate } \\
\hline & & Estimate & Chi-square & $\mathrm{Pr}>\mathrm{ChiSq}$ & Estimate & Chi-square & $\mathrm{Pr}>\mathrm{ChiSq}$ \\
\hline Intercept & & -0.1443 & 32.09 & $<.0001$ & -0.1497 & 12.45 & 0.0004 \\
\hline Growth stage & SI & 0.3705 & 200.58 & $<.0001$ & 0.3895 & 73.06 & $<.0001$ \\
\hline Growth stage & SII & 0.2073 & 43.38 & $<.0001$ & 0.2591 & 27.78 & $<.0001$ \\
\hline Growth stage & SIII & 0 & & & 0 & & \\
\hline Genotype & GNT-2 & 0.4197 & 218.18 & $<.0001$ & 0.4175 & 76.88 & $<.0001$ \\
\hline Genotype & $\mathrm{NDH}-98$ & 0.3327 & 83.19 & $<.0001$ & 0.4616 & 117.48 & $<.0001$ \\
\hline Genotype & Pratibha & 0 & & & 0 & & \\
\hline DCS & & 0.2596 & 25.95 & $<.0001$ & 0.2913 & 19.72 & $<.0001$ \\
\hline CURS1 & & 0.0296 & 0.37 & 0.5431 & 0 & & \\
\hline CURS2 & & 0.0535 & 6.44 & 0.0111 & 0 & & \\
\hline CURS3 & & -0.4059 & 110.98 & $<.0001$ & -0.4188 & 61.76 & $<.0001$ \\
\hline \multicolumn{8}{|c|}{ Reduced parameter robust linear test for demethoxycurcumin } \\
\hline Rho & & & & & 10.1158 & 12.68 & 0.0018 \\
\hline$R_{n} \wedge 2$ & & & & & 19.0271 & 19.03 & $<.0001$ \\
\hline
\end{tabular}

$\operatorname{Pr}<$ ChiSq approximately predicts the associated probability level after the selected variable has been entered or removed

$\operatorname{Pr}$ Probability, ChiSq Chi-square, Rho association or correlation, $R_{n} \wedge 2$ robust Wald-type association test

significant at $p<0.05$. Thus, DCS had a significant positive and CURS3 had a significant negative association with total curcuminoid yield in turmeric rhizome (Table 6).

\section{Discussion}

Gene expression studies can quantify the amount of functional mRNA (messenger ribonucleic acid) transcript in the experimental sample measured in terms of reversetranscribed cDNA (complementary deoxyribonucleic acid) concentration which codes for amino acids and functional proteins. After the identification and characterization of multiple type III PKS enzyme genes involved in the curcuminoid biosynthesis pathway $[19,20]$, it is now possible to study the differential gene expression patterns using reverse transcription quantitative real-time polymerase chain reaction (RTqPCR) assays in addition to protein-enzyme and product assays in different tissues of turmeric. The role of DCS and CURSs for curcuminoid biosynthesis in turmeric has been described by different studies (Fig. 4); however, the

Table 5 Association-based test of DCS and multiple curcumin synthases with bisdemethoxycurcumin

\begin{tabular}{|c|c|c|c|c|c|c|c|}
\hline \multirow[t]{2}{*}{ Parameter } & \multirow{2}{*}{$\begin{array}{l}\text { Class } \\
\text { label }\end{array}$} & \multicolumn{3}{|c|}{ Main effects } & \multicolumn{3}{|c|}{ CURS1 and CURS2 as a covariate } \\
\hline & & Estimate & Chi-square & $\operatorname{Pr}>$ ChiSq & Estimate & Chi-square & $\mathrm{Pr}>\mathrm{ChiSq}$ \\
\hline Intercept & & 0.3381 & 9.58 & 0.002 & 0.3586 & 12.19 & 0.0005 \\
\hline Growth stage & $\mathrm{SI}$ & 0.1514 & 1.82 & 0.1771 & 0.1847 & 2.8 & 0.094 \\
\hline Growth stage & SII & 0.1877 & 1.93 & 0.1644 & 0.0847 & 0.51 & 0.4768 \\
\hline Growth stage & SIII & 0 & & & 0 & & \\
\hline Genotype & GNT-2 & 0.5534 & 20.63 & $<.0001$ & 0.6544 & 32.23 & $<.0001$ \\
\hline Genotype & $\mathrm{NDH}-98$ & -0.0154 & 0.01 & 0.9216 & -0.1401 & 1.85 & 0.1741 \\
\hline Genotype & Pratibha & 0 & & & 0 & & \\
\hline DCS & & 0.3727 & 2.91 & 0.0881 & 0.0342 & 0.05 & 0.8294 \\
\hline CURS1 & & -0.2976 & 2.03 & 0.1537 & 0 & & \\
\hline CURS2 & & 0.0424 & 0.22 & 0.6389 & 0 & & \\
\hline CURS3 & & -0.618 & 13.99 & 0.0002 & -0.4367 & 11.46 & 0.0007 \\
\hline \multicolumn{8}{|c|}{ Reduced parameter robust linear test for bisdemethoxycurcumin } \\
\hline Rho & & & & & 1.5189 & 1.9 & 0.3859 \\
\hline$R_{n} \wedge 2$ & & & & & 2.7031 & 2.7 & 0.2588 \\
\hline
\end{tabular}

$\operatorname{Pr}<$ ChiSq approximately predicts the associated probability level after the selected variable has been entered or removed $\operatorname{Pr}$ Probability, ChiSq Chi-square, Rho association or correlation, $R_{n} \wedge 2$ robust Wald-type association test 
Table 6 Association-based test of DCS and multiple curcumin synthases with total curcuminoid

\begin{tabular}{|c|c|c|c|c|c|c|c|}
\hline \multirow[t]{2}{*}{ Parameter } & \multirow{2}{*}{$\begin{array}{l}\text { Class } \\
\text { label }\end{array}$} & \multicolumn{3}{|c|}{ Main effects } & \multicolumn{3}{|c|}{ CURS1 and CURS2 as a covariate } \\
\hline & & Estimate & Chi-square & $\operatorname{Pr}>$ ChiSq & Estimate & Chi-square & Pr $>$ ChiSq \\
\hline Intercept & & 1.0927 & 45.46 & $<.0001$ & 1.2257 & 128.64 & $<.0001$ \\
\hline Growth stage & $\mathrm{SI}$ & 0.7981 & 23 & $<.0001$ & 0.9247 & 63.49 & $<.0001$ \\
\hline Growth stage & SII & 1.0051 & 25.2 & $<.0001$ & 0.8874 & 50.23 & $<.0001$ \\
\hline Growth stage & SIII & 0 & & & 0 & & \\
\hline Genotype & GNT-2 & 2.1593 & 142.72 & $<.0001$ & 2.4428 & 405.65 & $<.0001$ \\
\hline Genotype & $\mathrm{NDH}-98$ & 0.1852 & 0.64 & 0.4247 & -0.2492 & 5.28 & 0.0216 \\
\hline Genotype & Pratibha & 0 & & & 0 & & \\
\hline DCS & & 1.545 & 22.71 & $<.0001$ & 0.5921 & 12.57 & 0.0004 \\
\hline CURS1 & & -0.5897 & 3.63 & 0.0567 & 0 & & \\
\hline CURS2 & & 0.0863 & 0.41 & 0.5201 & 0 & & \\
\hline CURS3 & & -2.4214 & 97.63 & $<.0001$ & -1.838 & 183.38 & $<.0001$ \\
\hline \multicolumn{8}{|c|}{ Reduced parameter robust linear test for total curcuminoid } \\
\hline Rho & & & & & 3.1409 & 3.94 & 0.1396 \\
\hline$R_{n} \wedge 2$ & & & & & 4.772 & 4.77 & 0.092 \\
\hline
\end{tabular}

$\mathrm{Pr}<$ ChiSq approximately predicts the associated probability level after the selected variable has been entered or removed

$\operatorname{Pr}$ Probability, ChiSq Chi-square, Rho association or correlation, $R_{n} \wedge 2$ robust Wald-type association test

correlation or directional association between the gene expression level and curcuminoids level in turmeric rhizome is still unfolded. In this experiment, three cultivars differing in curcuminoid contents were evaluated for DCS and CURSs gene expressions, and normalized expression values are association tested with curcuminoid contents (curcumin, demethoxycurcumin, and bisdemethoxycurcumin) measured at three different growth stages in turmeric cultivars.

The curcuminoid analysis results showed that a higher turmeric rhizome yield does not necessarily mean higher curcuminoid contents in the turmeric cultivars. The curcuminoid contents were higher in long-growth-duration cultivar than short-growth-duration cultivar irrespective of the rhizome yield (Table 1). Differential gene expression patterns were also observed in three turmeric cultivars yielding different amounts of curcuminoids (curcumin, demethoxycurcumin, and bisdemethoxycurcumin). In general, higher gene expressions were during active vegetative and rhizome development stage (SISII) of turmeric cultivars than reduced expression at maturity or senescence stage (SIII) under study except that DCS expression was decreasing in NDH-98 and CURS3 expression was decreasing in Pratibha throughout the growth stages (Fig. 1). Differential expression of CURSs genes was also reported to be positively correlated with the curcumin content in Curcuma spp. during the 3rd and 6th months (active vegetative and rhizome developmental stages); however, during the 9th month (maturity stage), the curcumin content increased and the putative CURSs gene expressions were downregulated [40]. These patterns in each cultivar might have some significant role to play for curcuminoid biosynthesis in different turmeric cultivars suggesting that the genotype and growth stages affect the DCS and CURSs expressions at different developmental stages in turmeric. It was also reported that the highest expression of multiple curcumin synthases in Curcuma caesia Roxb. was found at the peak of its vegetative stage and expression levels of CURSs decreased at the time of maturity [29]. Among the three cultivars under study, there was no significant difference in DCS, CURS1, CURS2, and CURS3 gene expressions between GNT-2 and Pratibha (higher curcumin and total curcuminoid yielding cultivars); however, their expressions differed in NDH-98 (lower curcumin and total curcuminoid yielding cultivar) (Table 2). DCS expression was downregulated whereas CURS2 expression was upregulated in lower curcumin and lower total curcuminoid yielding cultivar (NDH-98) as compared with higher curcumin and higher total curcuminoid yielding cultivars (GNT-2 and Pratibha) and vice versa (Table 2). There was no significant change in the CURS3 expression ( $<2$-fold change) among the cultivars. CURS3 expressions were also found lower in all the turmeric species differing in curcuminoid yield [24]. These results showed that there is a significant variation in $D C S$ and CURSs gene expressions in turmeric rhizome also affected by genotype and growth stages.

The expressions of CURSs genes were also found to be affected by soil, climate, and harvesting time; however, CURSs expressions were found positively correlated with the curcumin content at a particular agroclimatic zone [30]. The expression of curcumin synthase genes (CURSs) and subsequent curcumin production varied at the different developmental stages of the plant in 


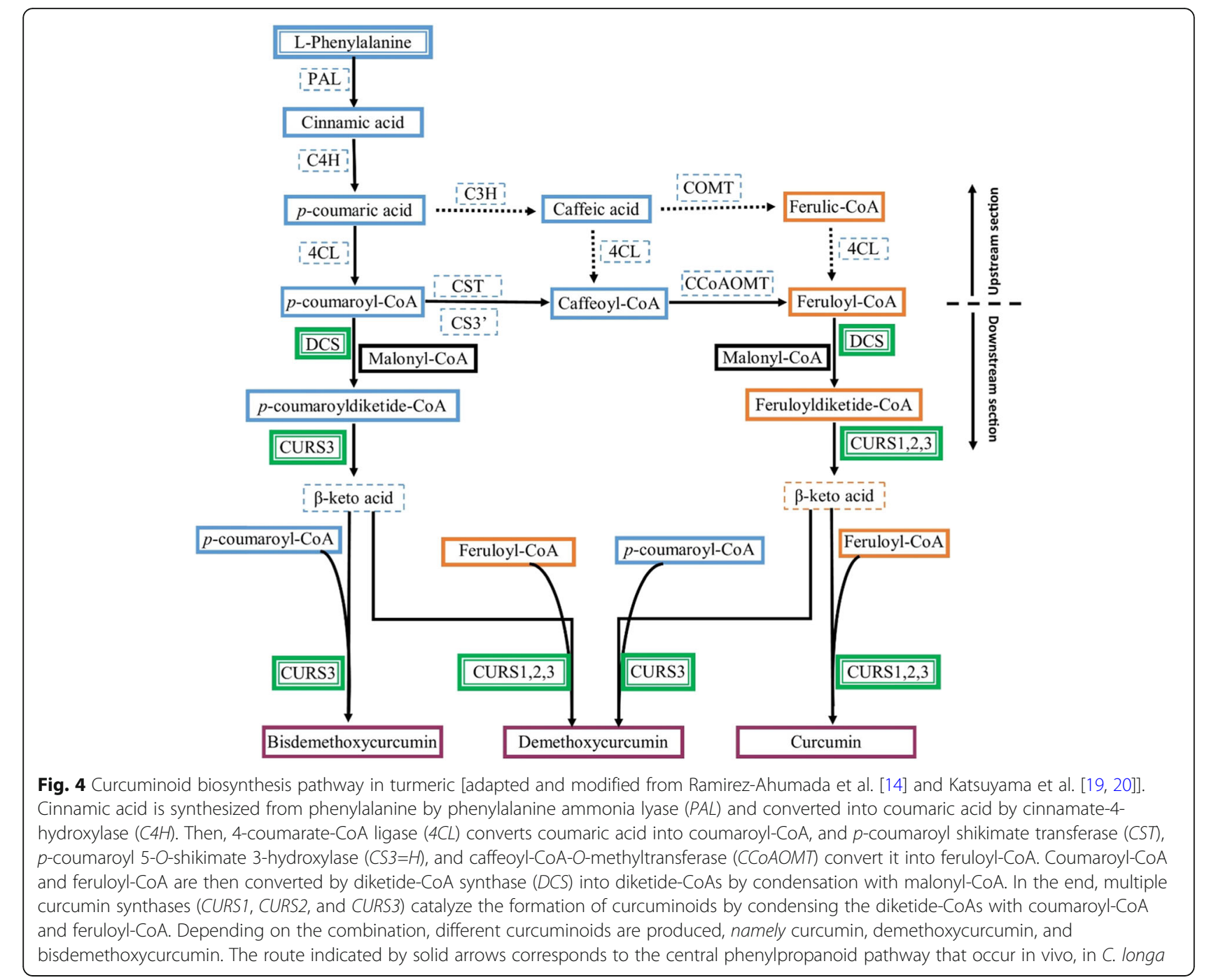

Curcuma spp. [29, 40]; however, we did not find any publications concerning DCS and CURSs expressions together in association with curcuminoid yield in turmeric to date. CURS1 and CURS2 expressions were also clustered as a distant group from DCS and CURS3 in this experiment (Fig. 3). Additionally, the gene expression studies alone cannot explain the magnitude and direction of the association between genes (DCS and CURSs) and gene products (curcuminoids). Thus, a more robust association-based test (robust regression) was applied for finding out the magnitude and direction of the associations. DCS and CURSs expressions in turmeric rhizome samples at three different growth stages were studied in association with biologically synthesized curcuminoids viz curcumin, demethoxycurcumin, bisdemethoxycurcumin, and total curcuminoid contents in turmeric rhizome samples for identifying any significant association between them. A robust regression analysis using the $\mathrm{M}$ estimator method was used for the association-based test which detects the outliers in the observed dataset and provides more precise information [32]. Associationbased tests between the gene expression and curcuminoids revealed that differential expressions of DCS, CURS1, CURS2, and CURS3 are responsible for the differential curcuminoid balance in turmeric rhizome, and their expressions are not always positively associated or correlated with curcuminoid yield. DCS expression had a significant positive but CURS3 expression had a significant negative association with curcumin, demethoxycurcumin, bisdemethoxycurcumin, and total curcuminoid yield in turmeric rhizome (Table 7).

On the other hand, the covariate effects of CURS1 and CURS2 were also found to be associated with curcuminoid balance in turmeric rhizome. CURS1 expression had a significant negative association with curcumin yield; however, CURS2 expression showed a significant positive association with demethoxycurcumin. The coregulated expression of CURS1 and CURS2 were also 
Table 7 Summary of the association-based tests between gene expression and curcuminoids

\begin{tabular}{|c|c|c|c|c|c|}
\hline \multirow[t]{2}{*}{ Gene ID } & \multicolumn{4}{|c|}{ Association test results } & \multirow[t]{2}{*}{ Remarks } \\
\hline & Curcumin & $\begin{array}{l}\text { Demethoxy- } \\
\text { curcumin }\end{array}$ & $\begin{array}{l}\text { Bisdemethoxy- } \\
\text { curcumin }\end{array}$ & $\begin{array}{l}\text { Total } \\
\text { curcuminoid }\end{array}$ & \\
\hline$\overline{D C S}$ & $+{ }^{* * * *}$ &,$+{ }^{* * *}$ &,$+ ¥$ & $+{ }^{*}{ }^{* * *}$ & DCS has a strong positive association with all the curcuminoids. \\
\hline CURS1 &,$-^{* * *}$ & NS & NS &,$- ¥$ & CURS1 expression is negatively associated with curcumin. \\
\hline CURS2 & NS &,$+^{*}$ & NS & NS & $\begin{array}{l}\text { CURS2 expression has a positive association with } \\
\text { demethoxycurcumin. }\end{array}$ \\
\hline CURS3 &,$-^{* * *}$ &,$-^{* * *}$ &,$-^{* * *}$ &,$-{ }^{* * *}$ & $\begin{array}{l}\text { CURS3 expression has a strong negative association with all the } \\
\text { curcuminoids. }\end{array}$ \\
\hline $\begin{array}{l}\text { CURS1 and } \\
\text { CURS2 }\end{array}$ & $¥$ & $* * *$ & NS & $¥$ & $\begin{array}{l}\text { Covariate effect of CURS1 and CURS2 have significant impact on } \\
\text { demethoxycurcumin. }\end{array}$ \\
\hline
\end{tabular}

\section{NS non-significant}

The results were adapted from Tables 3, 4, 5, and 6

+ , positive linear association

- , negative linear association

$¥$, significant at $p<0.10$

${ }^{* * *} p<0.001$; ${ }^{* *} p<0.01$; $p<0.05$

found significantly associated with demethoxycurcumin content in turmeric rhizome (Table 7). It was also reported that DCS and CURSs were capable of synthesizing curcuminoids through the major curcuminoid biosynthesis pathway in turmeric $[19,20]$ where CURS3 is capable of synthesizing all three curcuminoids; however, CURS1 and CURS2 are mainly responsible for the curcumin and demethoxycurcumin biosynthesis [20]. The results in this study suggested that the level of expression of DCS and CURSs genes have different individual effects on curcuminoid biosynthesis.

The results showed that higher curcuminoid yield in turmeric rhizome is associated with higher DCS and relatively lower CURS3 expressions, and vice versa. Similarly, higher CURS1 expression is associated with lower curcumin yield; however, higher CURS2 expression is associated with a higher demethoxycurcumin in turmeric rhizome, and vice versa (Table 7). This mechanism of co-expression of diketide-CoA synthase and multiple curcumin synthase genes involved in the curcuminoid biosynthesis pathway in turmeric rhizome revealed a significant effect on curcuminoid balance in different turmeric cultivars. Thus, diketide-CoA synthase and multiple curcumin synthase gene expressions are differentially associated with curcuminoid yield in turmeric rhizome, not always positively associated with individual curcuminoid. Further, enzymatic study regarding gene regulation of DCS and multiple curcumin synthases through genetic engineering and biotechnology approach will help to enhance curcuminoid content in turmeric rhizome or in vitro.

\section{Conclusions}

Gene expressions of diketide-CoA synthase and multiple curcumin synthases involved in the curcuminoid biosynthesis pathway in turmeric rhizome are influenced by genotype and growth stages. DCS and CURS3 expression patterns were closely associated and distinct from CURS1 and CURS2 expression patterns in turmeric rhizome. The association-based tests showed that DCS and CURSs gene expressions are not always positively associated with curcuminoid yield in turmeric rhizome. DCS expression had a significant positive but CURS3 expression had a significant negative association with curcumin, demethoxycurcumin, bisdemethoxycurcumin, and total curcuminoid yield. Curcumin, a major curcuminoid, is also found negatively associated with CURS1 expression. The co-regulated expressions of CURS1 and CURS2 were significantly associated with demethoxycurcumin content in turmeric rhizome. The gene regulation study of DCS co-expressed with multiple curcumin synthases (CURSs) and the overexpression of DCS through genetic engineering approach will help to enhance curcuminoid content in turmeric rhizome or in vitro for medicinal and industrial use.

\section{Supplementary Information}

The online version contains supplementary material available at https://doi. org/10.1186/s43141-020-00101-2.

Additional file 1: Table S1. DCS and multiple curcumin synthases gene expressions at different stages in turmeric rhizome. Table S2. Gene specific and reference primers used in qPCR assay. Table S3. Duncan's mean comparison of DCS, CURS1, CURS2 and CURS3 expressions among turmeric cultivars. Annex 1. SAS codes for association-based test using ROBUSTREG procedure.

Additional file 2: Fig S1. Chromatograms and calibration curves for curcumin, demothoxycurcumin and bisdemethoxycurcumin standards using HPLC. Fig S2. Chromatograms showing individual curcuminoid contents measured using HPLC at three stages of growth of three turmeric cultivars. Fig S3. Melt peak curves and gel electrophoresis results for DCS, CURS1, CURS2, CURS3 and reference gene Actin. In melt peak curves, single peak of each gene specific product was observed in each sample. In gel image, N represents 'NDH-98'; G represents, 'GNT-2'; and $P$ represents 'Pratibha' cultivars of turmeric under study. 


\section{Abbreviations}

CoA: Coenzyme A; CDNA: Complementary deoxyribonucleic acid; CURS1: Curcumin synthase 1; CURS2: Curcumin synthase 2; CURS3: Curcumin synthase 3; DCS: Diketide-CoA synthase; HPLC: High-performance liquid chromatography; mRNA: Messenger ribonucleic acid; PCR: Polymerase chain reaction; PKS: Polyketide synthase; RT-qPCR: Reverse transcription quantitative real-time PCR; SAS: Statistical Analysis System; UDG: Uracil DNA glycosylase

\section{Acknowledgements}

The research work and laboratory analysis were supported by the Department of Genetics and Plant Breeding, N. M. College of Agriculture, Navsari Agricultural University (NAU), Gujarat, India. The research opportunity provided by the Nepal Aid Fund Scholarship Scheme 2016-17 from the Government of India is highly acknowledged. We are privileged by the excellent coordination and laboratory facility available at Forest Biotechnology Laboratory in ASPEE College of Horticulture and Forestry, Sugarcane Research Station, and Food and Quality Testing Laboratory (FQTL), NAU. Suggestions and guidance during research work from Dr. A. V. Narwade, Dr. C. V. Kapadiya, Dr. Madhu Bala, Shreya Sen, Haidar Abbas, and the Qiagen Support team are highly acknowledged. Assistance during laboratory work from colleagues Ajay Gamit, Gaurav Patel, Vrunda Rawal, and Harshal Modi is acknowledged with appreciation.

\section{Authors' contributions}

DKA did the laboratory work, data analysis, and manuscript writing. KM guided the laboratory works, interpreted the results, and proofread the manuscript. VP guided the RT-qPCR, curcuminoid analysis, data analysis, and interpretation. RP ensured the funding for the laboratory work and guided the research work. VR and AB assisted during laboratory analysis and manuscript writing. Further, all the authors have read and approved the final manuscript and agreed for submitting the manuscript for publication in the Journal of Genetic Engineering and Biotechnology.

\section{Funding}

This research work was supported by the Department of Genetics and Plant Breeding, Navsari Agricultural University, Gujarat, India, for studying the gene expression in association with curcuminoid biosynthesis in turmeric cultivars. The research fund was utilized for purchasing reagents and doing laboratory works.

\section{Availability of data and materials}

The dataset supporting the conclusions of this article are included within the article and its additional file: Additional file 1: Table S1, Table S2, and Annex 1 .

\section{Ethics approval and consent to participate}

Not applicable.

\section{Consent for publication}

Not applicable.

\section{Competing interests}

The authors declare that they have no competing interests.

\section{Author details}

'Department of Genetics and Plant Breeding, N. M. College of Agriculture, Navsari Agricultural University, Navsari, Gujarat 396450, India. ${ }^{2}$ Department of Basic Science and Humanity, ASPEE College of Horticulture and Forestry, Navsari Agricultural University, Navsari, Gujarat 396450, India.

\section{Received: 18 September 2020 Accepted: 1 December 2020}

\section{Published online: 14 December 2020}

\section{References}

1. Sun W, Wang S, Zhao W, Wu C, Guo S, Gao H, Tao H, Lu J, Wang Y, Chen X (2017) Chemical constituents and biological research on plants in the genus curcuma. Crit Rev Food Sci Nutr 57(7):1451-1523. https://doi.org/10.1080/ 10408398.2016.1176554

2. Plotto A (2004) Turmeric: post-production management. Food and Agriculture Organization http://www.fao.org/fileadmin/user_upload/inpho/ docs/Post_Harvest_Compendium_-_Turmeric.pdf
3. Krup V, Prakash L, Harini A (2013) Pharmacological activities of turmeric (Curcuma longa Linn): a review. J Homeop Ayurv Med 2(4):133. https://doi. org/10.4172/2167-1206.1000133

4. Sasikumar B (2005) Genetic resources of Curcuma: diversity, characterization and utilization. Plant Genet Resour 3(2):230-251. https://doi.org/10.1079/ PGR200574

5. Vogel A, Pelletier J (1815) Examen chimique de la Racine de Curcuma. J Pharm 1:289-300

6. Sandur SK, Pandey MK, Sung B, Ahn KS, Murakami A, Sethi G, Limtrakul P, Badmaev V, Aggarwal BB (2007) Curcumin, demethoxycurcumin, bisdemethoxycurcumin, tetrahydrocurcumin and turmerones differentially regulate anti-inflammatory and anti-proliferative responses through a ROSindependent mechanism. Carcinogenesis 28(8):1765-1773. https://doi.org/ 10.1093/carcin/bgm123

7. Agrawal DK, Mishra PK (2010) Curcumin and its analogues: potential anticancer agents. Med Res Rev 30(5):818-860. https://doi.org/10.1002/med.20188

8. Aggarwal BB, Harikumar KB (2009) Potential therapeutic effects of curcumin, the anti-inflammatory agent, against neurodegenerative, cardiovascular, pulmonary, metabolic, autoimmune and neoplastic diseases. Int J Biochem Cell Biol 41(1):40-59. https://doi.org/10.1016/j.biocel.2008.06.010

9. Esatbeyoglu T, Huebbe P, Ernst IM, Chin D, Wagner AE, Rimbach G (2012) Curcumin-from molecule to biological function. Angew Chem Int Ed 51(22): 5308-5332. https://doi.org/10.1002/anie.201107724

10. Liu X, Wu D, Zhang Y, Zhou H, Lai T, Ding W (2016) RNA-Seq analysis reveals candidate targets for curcumin against Tetranychus cinnabarinus. Biomed Res Int 2016:2796260. https://doi.org/10.1155/2016/2796260

11. Moghadamtousi SZ, Kadir HA, Hassandarvish P, Tajik H, Abubakar S, Zandi K (2014) A review on antibacterial, antiviral, and antifungal activity of curcumin. Biomed Res Int 2014:186864. https://doi.org/10.1155/2014/186864

12. Rathaur P, Raja W, Ramteke P, John SA (2012) Turmeric: the golden spice of life. Int J Pharm Sci Res 3(8):1987

13. Katsuyama Y, Matsuzawa M, Funa N, Horinouchi S (2008) Production of curcuminoids by Escherichia coli carrying an artificial biosynthesis pathway. Microbiol 154(9):2620-2628. https://doi.org/10.1099/mic.0.2008/018721-0

14. Ramirez-Ahumada MC, Timmermann BN, Gang DR (2006) Biosynthesis of curcuminoids and gingerols in turmeric (Curcuma longa) and ginger (Zingiber officinale): identification of curcuminoid synthase and hydroxycinnamoyl-CoA thioesterases. Phytochemistry 67(18):2017-2029. https://doi.org/10.1016/j.phytochem.2006.06.028

15. Katsuyama Y, Matsuzawa M, Funa N, Horinouchi S (2007) In vitro synthesis of curcuminoids by type III polyketide synthase from Oryza sativa. J Biol Chem 282(52):37702-37709. https://doi.org/10.1074/jbc.M707569200

16. Kita T, Imai S, Sawada H, Kumagai H, Seto H (2008) The biosynthetic pathway of curcuminoid in turmeric (Curcuma longa) as revealed by ${ }^{13} \mathrm{C}$ labeled precursors. Biosci Biotechnol Biochem 72(7):1789-1798

17. Koo HJ, McDowell ET, Ma X, Greer KA, Kapteyn J, Xie Z, Descour A, Kim H, Yu Y, Kudrna D, Wing RA, Soderlund CA, Gang DR (2013) Ginger and turmeric expressed sequence tags identify signature genes for rhizome identity and development and the biosynthesis of curcuminoids, gingerols and terpenoids. BMC Plant Biol 13(1):27. https:/doi.org/10.1186/1471-2229-13-27

18. Sheeja TE, Deepa K, Santhi R, Sasikumar B (2015) Comparative transcriptome analysis of two species of Curcuma contrasting in a high-value compound curcumin: insights into genetic basis and regulation of biosynthesis. Plant Mol Biol Report 33(6):1825-1836. https://doi.org/10.1007/s11105-015-0878-6

19. Katsuyama Y, Kita T, Funa N, Horinouchi S (2009) Curcuminoid biosynthesis by two type III polyketide synthases in the herb Curcuma longa. J Biol Chem 284(17):11160-11170. https://doi.org/10.1074/jbc.M900070200

20. Katsuyama Y, Kita T, Horinouchi S (2009) Identification and characterization of multiple curcumin synthases from the herb Curcuma longa. FEBS Lett 583(17):2799-2803. https://doi.org/10.1016/j.febslet.2009.07.029

21. Annadurai RS, Neethiraj R, Jayakumar V, Damodaran AC, Rao SN, Katta MA, Gopinathan S, Sarma SP, Senthilkumar V, Niranjan V, Gopinath A, Mugasimangalam RC (2013) De novo transcriptome assembly (NGS) of Curcuma longa $\mathrm{L}$. rhizome reveals novel transcripts related to anticancer and antimalarial terpenoids. PLoS One 8(2):e56217. https://doi.org/10.1371/ journal.pone.0056217

22. Resmi MS, Soniya EV (2012) Molecular cloning and differential expressions of two CDNA encoding type III polyketide synthase in different tissues of Curcuma longa L. Gene 491(2):278-283. https://doi.org/10.1016/j.gene.2011.09.025

23. Deepa K, Sheeja T, Rosana O, Srinivasan V, Krishnamurthy K, Sasikumar B (2017) Highly conserved sequence of CIPKS11 encodes a novel polyketide 
synthase involved in curcumin biosynthesis in turmeric (Curcuma longa L.) Ind Crop Prod 97:229-241

24. Li D, Ono N, Sato T, Sugiura T, Altaf-UI-Amin M, Ohta D, Suzuki H, Arita M, Tanaka K, Ma Z, Kanaya S (2015) Targeted integration of RNA-Seq and metabolite data to elucidate curcuminoid biosynthesis in four Curcuma species. Plant Cell Physiol 56(5):843-851. https://doi.org/10.1093/pcp/pcv008

25. Hayakawa H, Minaniya Y, Ito K, Yamamoto Y, Fukuda T (2011) Difference of curcumin content in Curcuma longa L.(Zingiberaceae) caused by hybridization with other Curcuma species. Am J Plant Sci 2(02):111-119

26. Sandeep IS, Kuanar A, Akbar A, Kar B, Das S, Mishra A, Sial P, Naik PK, Nayak S, Mohanty S (2016) Agroclimatic zone based metabolic profiling of turmeric (Curcuma Longa L.) for phytochemical yield optimization. Ind Crop Prod 85:229-240. https://doi.org/10.1016/j.indcrop.2016.03.007

27. Anandaraj M, Prasath D, Kandiannan K, Zachariah TJ, Srinivasan V, Jha A, Singh B, Singh A, Pandey V, Singh S (2014) Genotype by environment interaction effects on yield and curcumin in turmeric (Curcuma longa L.). Ind Crop Prod 53:358-364

28. Sandeep IS, Sanghamitra N, Sujata M (2015) Differential effect of soil and environment on metabolic expression of turmeric (Curcuma longa cv. Roma). Indian J Exp Biol 53(6):406-411

29. Behar N, Tiwari K, Jadhav S (2016) Semi-quantitative expression studies of genes involved in biosynthesis of curcuminoid in Curcuma caesia Roxb. Indian J Biotechnol 15(4):491-494

30. Sandeep IS, Das S, Nasim N, Mishra A, Acharya L, Joshi RK, Nayak S, Mohanty S (2017) Differential expression of CURS gene during various growth stages, climatic condition and soil nutrients in turmeric (Curcuma longa): towards site specific cultivation for high curcumin yield. Plant Physiol Biochem 118: 348-355. https://doi.org/10.1016/.plaphy.2017.07.001

31. Ayer D, Modha K, Parekh V, Patel R, Ramtekey V, Bhuriya A (2018) Comparative gene expression study between two turmeric (Curcuma longa L.) cultivars. JOSAC 27(2):131-137

32. Seo M, Kim K, Yoon J, Jeong JY, Lee H-J, Cho S, Kim H (2016) RNA-seq analysis for detecting quantitative trait-associated genes. Sci Rep 6:24375. https://doi.org/10.1038/srep24375 https://www.nature.com/articles/srep243 75\#supplementary-information

33. Rousseeuw PJ, Leroy AM (2005) Robust regression and outlier detection. Wiley

34. MacRae E (2007) Extraction of plant RNA. Methods Mol Biol 353:15-24. https://doi.org/10.1385/1-59745-229-7:15

35. Bustin SA, Benes V, Garson JA, Hellemans J, Huggett J, Kubista M, Mueller R, Nolan T, Pfaffl MW, Shipley GL, Vandesompele J, Wittwer CT (2009) The MIQE guidelines: minimum information for publication of quantitative realtime PCR experiments. Clin Chem 55(4):611-622. https://doi.org/10.1373/ clinchem.2008.112797

36. Taylor S, Wakem M, Dijkman G, Alsarraj M, Nguyen M (2010) A practical approach to RT-qPCR - publishing data that conform to the MIQE guidelines. Methods 50(4):S1-S5. https://doi.org/10.1016/j.ymeth.2010.01.005

37. Pfaffl MW (2001) A new mathematical model for relative quantification in realtime RT-PCR. Nucleic Acids Res 29(9):e45. https://doi.org/10.1093/nar/29.9.e45

38. Vandesompele J, De Preter K, Pattyn F, Poppe B, Van Roy N, De Paepe A Speleman F (2002) Accurate normalization of real-time quantitative RT-PCR data by geometric averaging of multiple internal control genes. Genome Biol 3(7):RESEARCH0034

39. SAS (2015) The ROBUSTREG procedure. Statistical Analysis System, Cary

40. Santhoshkumar R, Yusuf A (2020) Comparative differential expression of CURS genes and determination of curcumin content at different growth stages of Curcuma longa L. and its wild relative C. zanthorrhiza Roxb. Genet Resour Crop Evol. https://doi.org/10.1007/s10722-020-00970-z

\section{Publisher's Note}

Springer Nature remains neutral with regard to jurisdictional claims in published maps and institutional affiliations.

\section{Submit your manuscript to a SpringerOpen ${ }^{\circ}$ journal and benefit from:}

- Convenient online submission

- Rigorous peer review

- Open access: articles freely available online

- High visibility within the field

- Retaining the copyright to your article

Submit your next manuscript at $\boldsymbol{\nabla}$ springeropen.com 